Advances in Dynamical Systems and Applications.

ISSN 0973-5321, Volume 16, Number 1, (2021) pp. 335-353

(C) Research India Publications

https://dx.doi.org/10.37622/ADSA/16.1.2021.335-353

\title{
The Decision Making Method for Reconfiguration of Adaptive Infocommunication Systems
}

\author{
Loginov I.V. ${ }^{1}$, Kuzichkin O.R. ${ }^{2}$, Eremenko V.T. ${ }^{1}$, \\ Vasilyev G.S. ${ }^{2}$, Eremenko S.V. ${ }^{1}$, Surzhik D.I. ${ }^{2}$ \\ ${ }^{1}$ Orel state University named after I. S. Turgenev, Orel, 302026, Russia. \\ ${ }^{2}$ Belgorod State University, Belgorod, 308015, Russia.
}

\begin{abstract}
The adaptation both information and communication systems to variable external factors is implemented through the modernization activities. In this paper the problem of decision-making for adaptive system reconfiguration under uncertainty is considered. The decision-making method is used to detect a need for reconfiguration, built a set of reconfigurations plans and choose the preferable one based on data collection from diagnostic sensor network. Integral decision-making criterion combines the criterion for selecting a suitable reconfiguration moment and alternative. The main idea of the proposed method is to combine the multifactor active diagnostic model, weighted utility and preference theory, decision-making technique under uncertainty with comparison methods for fuzzy trees with incomplete requirement. The general result is achieved by reducing the uncertainty of diagnostic data. It is expected that the proposed decision-making method will help to improve the systems' suitability in the case of uncertainty.
\end{abstract}

Keywords: IT system, adaptation, decision-making, criterion, uncertainty, suitability, reconfiguration.

\section{INTRODUCTION}

The development of large information and communication systems for organizations and enterprises has led to a significant increase in their structural and functional complexity. Management information systems, distributed computing systems, distributed networks of situation centers, cloud storage and data centers, telecommunications systems include dozens of subsystems with hundreds of heterogeneous components. They combine technology equipment, communication 
networks, computing and information systems, analytical resources. The purpose of distributed information and communication environments is to automate the execution of technological processes at extended enterprises by providing a set of information and communication services: automation, computerization, information and telecommunications.

The development of such complex systems is implemented through the modernization activities. For infocommunications environments we need to simultaneously implement a significant number of IT projects with increased system's efficiency.

The decision-making problem in IT system reconfiguration is currently being solved by multicriterial methods with experts and optimization techniques. However the situation of system development characterized by the uncertainty of internal and external factors such as goas of enterprise informatization, IT components using intensity, resources flow, IT services request flow and so on. This situation requires not only decision-making within selection a variant of modernization but also combined selection of modernization moment and variant. Thus, the proposal of a decision-making method for choosing the directions within the reconfiguration of adaptive infocommunication system under the conditions of system function uncertainty is relevant now.

\section{THE REVIEW OF DECISION MAKING APPROACHES FOR INFOCOMMUNICATION SYSTEM RECONFIGURATION}

The development of complex infocommunicational systems due to changes in external and internal factors determines effective decision-making for a rational choice of modernization alternatives. With the development of information and communication technologies such as Internet of Things, social media, 3D printing and with the increased enterprise diversification and distributing, a new methods of decision-making under conditions of uncertainly are required. The control method to reconfigure the systems is crucial for the total performance of based enterprise $[1,2]$. The base goal of decision-making in reconfigurable system is to save reconfiguration time, cost, and effort [3].

The problem of infocommunication system reconfiguration and particularly decisionmaking problem are very important in fast developing extended enterprises. There are many known approaches to reconfiguration including methods and techniques of management development $[2,4,5]$. The review of the main approaches used in the analysis, design and modernization of complex systems is given in [5]. The theory of complex systems structural dynamics is used for IT system reconfiguration [4]. In hierarchical systems the modernization problem are considered with complex effects. Synthesis of the optimal reconfiguration plan may be realized by hierarchical systems of heterogeneous network structure [6] and linking the objectives between the strategic and operational level [7].

There are many kinds of reconfiguration systems decision-making approach: flexible and reconfigurable manufacturing systems [8,9], distribution network [10], dynamic 
cell formation [11], information fusion systems [12], cognitive radios [13]. A special decision making support is widely used. For example, a generic case-based reasoning decision support system for reconfiguration purpose based on past experience to facilitate the reconfiguration decision making process was proposed in the [14].

Different mathematical mechanisms are used to solve the decision-making reconfiguration problem. The Bellman-Zadeh method with Pareto objective space was adopted in the fuzzy resolution methodology proposed in [15] to solve fuzzy multicriteria decision making problem. The Tabu Search algorithm (TS) is used to solve reconfiguration problem in the [16] due to its excellent search ability. In [10] the multi-criteria decision making based on the ELECTRE II method was applied to distributed network reconfiguration in case of cascading effects of faults, cyber attacks and natural disasters. In the [17] a decision support system was proposed to create candidate configurations and select a suitable configuration considering a knowledge-based multi-criteria decision making approach based on ontology and TOPSIS. In [18] a dynamic reconfiguration algorithm based on SVM method for the cyber- physical system environment was proposed. In [19] a bi-objective mathematical model based on Non-dominated Sorting Genetic Algorithm of Dynamic Cell Formation Problem with uncertainty conditions and social criteria between the minimization of the total costs and the maximization of social issues with the minimization of potential machine hazards and maximizing job opportunities was developed. A reconfiguration decision-making method based on a Game-Theory algorithm and on the Gale-Shapley model is proposed in [1].

The one of the main conditions of system reconfiguration decision-making is a change in the requirements of alternatives [20, 21, 22]. To solve this problem there are dynamic preferences considered within the uncertainty of temporal changes of requirements [23, 24]. The time dependences constrains in decision-making for reconfigurable systems are widely viewed in the literature. The model of discounted integral effect are considered in [25] based on the discounting and time preferences between alternatives. The papers [26, 27] view the base framework of decisionmaking in the conditions of dynamic change of alternatives' preferences. The preferences of active subjects changing over time is using for the temporal approach accounting of alternatives [29] for dynamic nature of decision-making. The approach of net discounting is used for the implementation of a complex system [23].

There are many discounting functions such as hyperbolic, quasi-hyperbolic, exponential, linear $[28,29]$ which describe the preferences between alternatives. The information about both uncertainties of the factors' values and the change of uncertainty depending on the conditions of decision-making under risk [24] are used for creating discounting functions. They allow creating decision-making mechanism in the conditions of non-stationary system behavior. Also different time-dependent criterion functions are used to solve the problems of alternatives selection and ranking: fuzzy temporal utility to search necessary information in databases in [30], weighted utility functions for scheduling in distributed computing [31], the base questions of a probabilistic dynamic method of a consumer choice [32]. 
Other problem in the complex system reconfiguration is to determinate the moment of control action. To decide this problem the effective monitoring system is needed. Distributed infocommunicational environments include diagnostic system based on sensor network. It can include special sensors and data acquisition system based on IoT technology $[8,33]$. In [8] the decision-making system with the data acquisition system based on IoT technology combined with flexible and reconfigurable manufacturing systems were proposed. The planning of IoT data by reconfigurable system for manufacturing (RMS) was applied in [34]. A modular reconfigure system based on 3D printing and the concept of SMARTLAM was proposed in [34].

For a complex reconfiguration problem multistage methods are proposed. For example, [35] concerns mathematical models to support the design, reconfiguration and scheduling of the reconfigurable system: optimization model allows to manage the reconfiguration at fixed periods and allocation model uses to allocate the jobs into the components.

The purpose of paper [36] is to formulate a robust production system with minimal cost and maximum service level that can respond efficiently to the stochastic input demand.

Problem of reconfiguration the autonomous IT system has some distinctions. The method for autonomous decision making with multiple conflicting and operational objectives with a time-varying propagation environment was proposed in [37].

Many viewed methods are preventive and off-line reconfiguration planning approaches, thus missing updated accurate data about system components activities and task flow. This may result to non-optimal and non-suitable decision especially in the conditions of environments and goal uncertainty. Thus, the problem to develop a new decision-making method of selection the modernization alternatives is relevant now.

\section{DECISION MAKING PROBLEM UNDER SYSTEM RECONFIGURATION}

Adaptive infocommunicational systems are characterized by the fact that over time the composition, structure, and the functions list ceases to satisfy users' requirements, and also changing regulations and external factors. Thus, the suitability of technical systems decreases over time. The solution of such a problem is achieved by controlled targeted reconfiguration, that is, changing the composition, structure and functions of the system through modernization and structural-parametric optimization. The decision-making for suitable alternative of modernization cycle is immediate reconfiguration.

Decision-making via modernization of an infocommunicational adaptive system is implemented by chosen moment of modernization and alternative plan through a set of alternatines. The goal of a decision-making system is to develop manageable adaptive infocommunicational system with the aim to maximize modernization IT components' positive effect and minimize the cost of reconfigurations activities. 
The problem may be described by the following objectives:

1) the infocommunication system $S$ includes several IT components $S_{i}$ that can be upgraded by the management system $M S:\left\{S_{i}\right\}, i=(1, I)$.

2) there are many alternatives to IT components modernization $A_{i}=\left\{A_{i j}\right\}: S_{i} \stackrel{A_{i j}}{\longrightarrow} S_{i j}^{*}$, that can be used to improve the IT system.

3) the external conditions are characterized by:

- reducing the duration of components' activity by its life cycle processes (and accordingly increasing the frequency of modernization);

- increasing the structural and functional complexity of the IT system;

- increasing the level of automation and the number of alternatives to its implementation;

- increasing the external dynamics.

4) the current situation on reconfiguration process leads to the following consequences:

- longer time to detect the need for reconfiguration;

- increasing intensity of modernization requests;

- reducing the effect from reconfiguration actions.

5) modernization requests of IT component $S_{i}$ into the uncertainty flow $\lambda_{\text {ITreq }}(t)$.

6) there are system requirements $R S=\left\{r s_{i}\right\}$ for the ranking alternatives problem, determining the characteristics of the modernized IT component.

7) the moment of modernization activity is unknown.

8) for reconfiguration of the system $S$, resources $R_{S}$ are used: $R_{S}=\sum_{i=0}^{I} R_{i}$. The amount of resources used for the decision-making is under limit.

The problem is to find the modernization alternatives from the set $A_{i j} \in A_{i}$ and an optimal reconfiguration moment $T_{i j}: A_{i j}\left(T_{i j}\right) \succ A_{i k}(t), \forall k \neq j$, to maximize the effect of modernization $E\left(A_{i j}\left(T_{i j}\right)\right)=\max _{A_{i j} \in A} E$. 


\section{ADAPTIVE INFOCOMMUNICATION SYSTEM MODEL}

The reconfigurable infocommunication system $S$ includes several IT components $S_{i}: S=\left\{s_{1}, \ldots, S_{I}\right\}$. Due to a change in external conditions, the suitability of the IT components $S_{i}$ decreases (Figure 1). If a drop in IT components suitability is detected above the critical value $k_{i}(t)<k^{\text {critical }}$, the suitability level is restored $k_{i} \rightarrow k^{\text {restore }}$ in duration of time $t^{\text {modernization }}$ by means of reconfiguration (modernization) measures for alternative $A_{i j} \in A_{i}$. Nonsuitable alternative $A_{i k} \in A_{i}$ characterized by other moment of reconfiguration $T_{i k}$ or metrics of reconfiguration activities. For one IT component, an alternative $A_{k}$ may be more preferable than optimal $A_{i k} \in A_{i}$, $A_{k}\left(T_{k}\right) \succ A_{j}\left(T_{k}\right)$, but for overall system optimal alternative and reconfiguration moment $\left\langle A_{i k}, T_{i k}\right\rangle$ are more preference than any others.

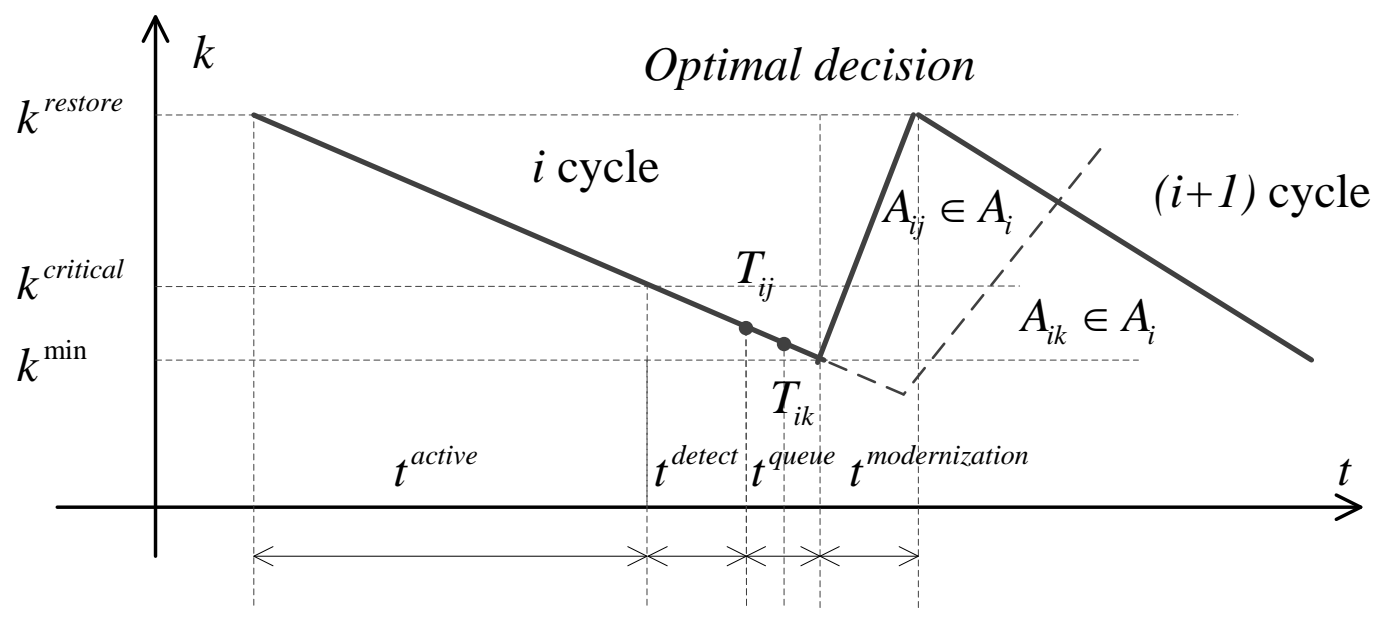

Figure 1. Graph of service availability quotient for IT components as a function of time.

The effect of the reconfigurable system may be determined by sum of IT components effects calculated through the service availability quotient:

$$
E(S)=\sum_{i=1}^{I} \alpha_{i} \bar{k}_{i}
$$

where $\alpha$-importance (significance) factor of IT component, it depends on time; $\bar{k}-$ average value of service availability quotient for IT components 


$$
\bar{k}=\int_{t_{\text {create }}}^{t_{\text {utilize }}} k(t) \approx k^{\text {restore }}+k^{\mathrm{min}} / 2 \text {. }
$$

The identified effects are enhanced in the typical system conditions:

- limited capacity to manage the modernization of samples due to different affiliation and subordination relationships (interacting samples within an adaptive multi-component system are usually operated by different departments); tools);

- heterogeneity of used components (wide range of technical and software

- uncertainties of external conditions (sources and time points of modernization requests reception are not determined);

- absence of standard design solutions (due to novelty of objects);

- the risks of modernization projects and creating new components.

Known approaches to reconfiguration management lead to:

- a decrease in the suitability of the systems;

- an increase of resource requirements for reconfiguration (life cycle support).

At the same time, the development of administrative procedures for supporting the life cycle (reducing the design, development, implementation, resource consumption, labor intensity) does not compensate for the decrease in the suitability of the system within the framework of the model under consideration.

\section{INTEGRAL DECISION-MAKING CRITERIA FOR INFORMATION SYSTEM RECONFIGURATION}

The non-linearity determines system reconfiguration it as a class of complex organizational and technical problems. The multicriteria analysis methods allow searching the optimal solution for problem in the case of system uncertainty.

To solve the problem of systems reconfiguration an integrated approach to decision making for reconfiguration in conditions of uncertainty are proposed in this article. It is based on an integral decision making reconfiguration criterion, combining a multifactor diagnostic model and maximization of the integral expected utility.

The main features of the proposed criteria are:

-multifactor active diagnostic model based on the data from sensor networktype system;

- theory of the weighted utility and preference for reconfiguration alternatives ranking;

- decision-making under uncertainty with incomplete requirements; 
- fuzzy comparison of functional trees based on feature-structural similarity.

The decision-making for reconfiguration bases on the diagnostic data from information sensor network.

The key concepts of proposed method are:

- the effect from reconfiguration actions (usually made via modernization projects) are depending on time $t$ and moment of action $t_{r c f g}$;

- the preference between alternatives $A_{j}$ and $A_{k}$ is mean that total effect of system $S$ is more with alternative $A_{j}$ than with $A_{k}$.

- the uncertainty of reconfiguration process data may be decreased by adding new accounting data from special sensor network.

The integral decision-making method for system reconfiguration is divided into four base stages.

Stage I: In this stage the need of IT components modernization and optimal moments $T_{i k}$ of it is determined.

The main idea of the stage is identifying the state of reconfigurable infocommunication system based on retrospective and current information. It is based on methods and techniques for estimating a weighted state graph, characterized by a complex decision criterion based on fuzzy production rules for combining diagnostic data in conditions of uncertainty.

The main achieved results are:

- reducing the time to detect the need for reconfiguration;

- estimating changes in the utility function for IT components over time $\xi\left(t, t_{r c f g}\right)$.

This stage includes the following sequential operations:

1) the network $m s_{i}^{m}$ monitors the system state $S_{i}$ (where $i$-reconfiguration cycle).

2) based on the results of monitoring, an operational diagnostic model $\widehat{S}_{i}$ is being built.

3) based on the diagnostic model $\widehat{S}_{i}$, the utility function over time $\xi_{i j}\left(t, t_{r c f g}\right)$ is estimated.

4) based on the weighted utility function, an importance (significance) factor $\alpha_{i j}(t)$ of IT component is calculated. 
5) optimal moments of reconfiguration $T_{i k}$ for all potential reconfigurable IT components are determined.

Stage II: In this stage the set of alternatives is generated.

The main idea of the stage is forming a set of alternatives of IT components modernization actions (plans or projects). It is based on morphology designing methods for generating a base set of alternatives for all potentially modernized IT components and Pareto-optimal based method to reduce a number of alternatives.

The main achieved result here is to generate initial set of alternatives to enable decision-making process.

This stage includes the following sequential operations:

1) for all potentially modernized IT components $S_{i j}$, a set of modernization plans $S_{i j} \rightarrow\left\{A_{i j k}\right\}$ is generated.

2) for all components $S_{i j}$ only Pareto-optimal ones remain, all others are deleted from the components alternatives set.

3) a unified set of alternatives from all components is generated.

Stage III: In this stage the new requirement system $R S_{i}$ and the effective criteria are determined.

The main idea of the stage is to form new more suitable requirements from incomplete conflicting needs and predict service availability quotient for IT components $k_{i j}\left(R S_{i j}\right)$. It is based on multivariable evaluation with inconsistent heterogeneous requirements to a state of components, which takes into account uncertainty of decision-making reconfiguration moments.

The main achieved results are:

- reducing the uncertainty of requirements for the reconfigurable system;

- improving the accuracy of forecasts by using additional information on the qualitative characteristics of alternatives.

This stage includes the following sequential operations:

1) based on basic system requirements $R S$ with the functionality tree template $\overline{F S}$, alternatives functionality trees $\left\{F S_{i}\right\}$ are created.

2) uniting a set of the functionality trees $F S_{i}^{+}$into one extended tree of alternatives $\overline{F S}^{+}$.

3) determining requirements $R S_{i}$ based on an extended tree of alternatives $\overline{F S}^{+}$. 
4) estimating positive effect $\hat{S}_{i j} \in \hat{S}_{i}$ for all alternatives $A_{i}=\left\{A_{i j}\right\}: S_{i} \stackrel{A_{i j}}{\longrightarrow} S_{i j}^{*}$ based on new requirements $R S_{i}$.

Stage IV: At this stage modernization alternatives are determined from the set $A_{i j} \in A_{i}$ by multicriteria decision.

The main idea of the stage is ranking the alternatives by value of expected utility for reconfiguration plan. It is bases on stochastic optimization preprocessing of alternatives characteristics to consider the expected utility by a features tree [38] and decision-making technique under uncertainty.

The basic achieved result is an increased effect of modernization plan. Thus, the suitability of reconfigurable system is increasing by a proposed method.

This stage includes the following sequential operations:

1) calculate the conditions value of the functional parameters $f s(t)$.

2) calculate the quality indicator value $q s_{i j}(t)$ for all alternatives.

3) estimate the expected utility on features tree with quality indicator.

4) find the ideal object $A^{*} \Rightarrow F S^{*}$ from a set of alternatives $A_{i j} \in A_{i}$ and requirements $R S_{i}$.

5) calculate the decision tree $\Phi^{+}$.

6) find the ranks $R=\left\{r_{i}\right\}$ of reconfiguration action alternatives.

7) select the modernization alternatives from a set $A_{i j} \in A_{i}$ with the minimal rank. conditions:

There are several decision trees $\Phi^{+}$used for decision-making in special

- under the uncertainty of implementation time, criteria in [39] for condition values of the functional parameters is used;

- under the incomplete requirements, method in [40] may be used, which implies restructuring of the requirements system tree by accounting values of additional functional characteristics of the alternatives.

- under the uncertain intensity of components' use, method in [41] is suitable, which minimizes the total cost of modernization resources for the system by a stochastic programming method.

\section{THE IMPLEMENTATION OF DECISION-MAKING CRITERIA FOR}




\section{INFORMATION SYSTEM RECONFIGURATION}

For implementation of the proposed decision-making method we consider a typical situation: a number of IT components of the reconfigurable system are increased several times. This situation leads to an increase of the number of required resources $R_{S}$ for the system's operation.

Modeled situation:

The decision-making is done assuming the resource limits: $R_{S}=\sum_{i=0}^{I} R_{i} \leq R_{\mathrm{lim}}$. We expect that resource limits are growing proportionally with the number of IT components but in practice resources are limited, and also we have an external consumer factor and decreasing component lifetime. The ratio between required resources and limits is shown in the Figure 2, where $v=R_{\text {lim }} / R_{S}$. The graphs show that with increase of the number of IT components and decrease of the active lifecycle, the ratio of limited to required resources is decreasing (Figure 3). Figure 3 shows 3D-plot of limits to required resources ratio.

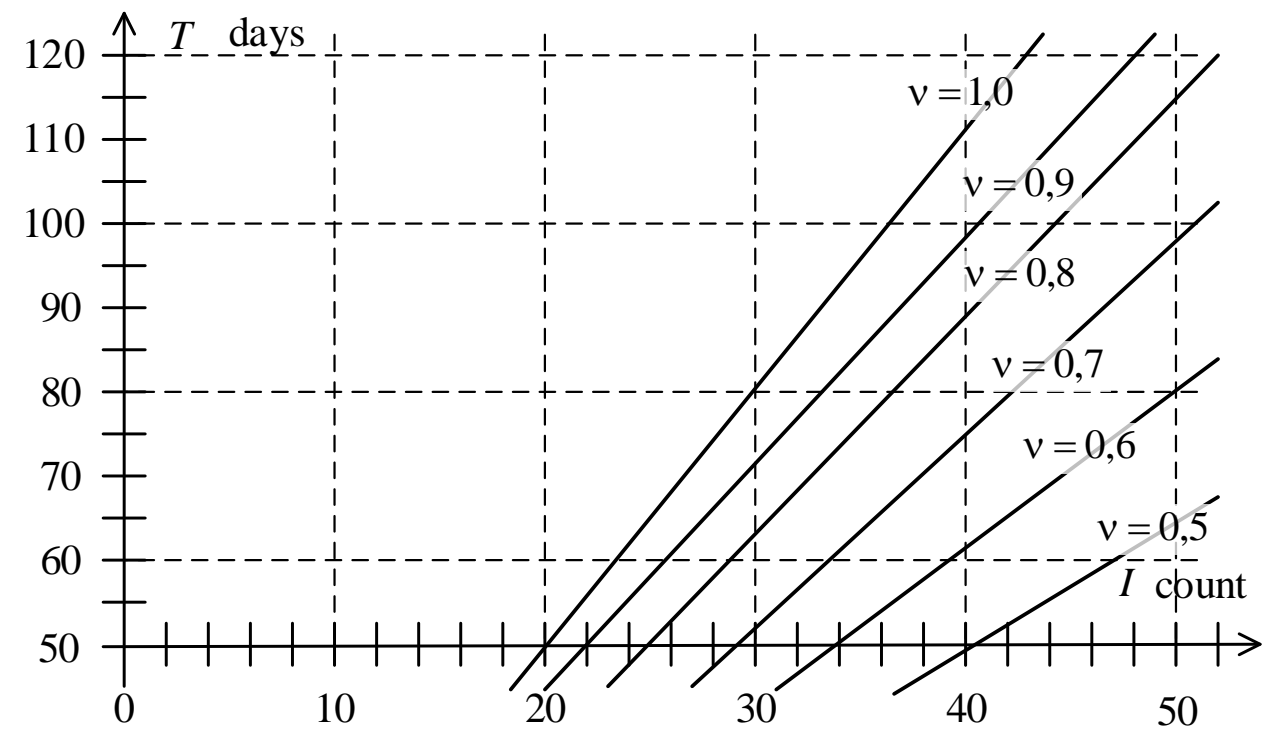

Figure 2. Graphs of limits-to-required resources ratio. 


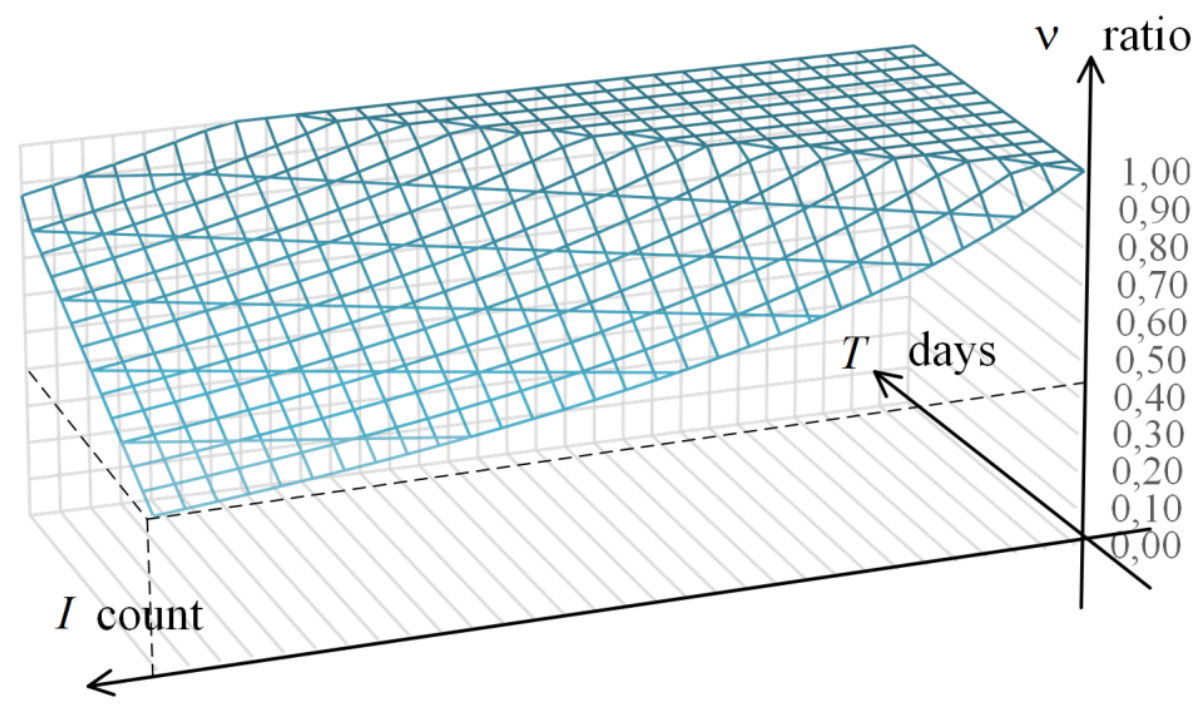

Figure 3. 3D-plot of limits-to-required resources ratio.

A proposed adaptive reconfiguration decision-making method is intended to improve the suitability of the systems by two main effects:

- determine the optimal moments of reconfiguration $T_{i k}$ for all potential reconfigurable IT components via decreasing detection time $t^{\text {detect }}$;

- select the modernization alternatives from a set $A_{i j} \in A_{i}$.

There are two main factors influencing the experiments:

- a number of IT components - I (we analyze multicomponent IT system with 20-50 active IT services);

- the time of IT components active lifecycle and modernization $-T$ (we analyze medium length of IT components lifecycle $\sim 2-3$ months between modernizations).

Some experiments showed that depending on the external conditions, the use of a sensor network and an adaptive diagnostic model allows reducing the detection time $t^{\text {detect }}$ by 10-15 percent compared to typical technological solutions used in infocommunication systems. The result of decision-making is a suitable moment of reconfiguration $T_{i k}$ as a control action.

The impact of the detection time $t^{\text {detect }}$ on the system's suitability is shown in Figure 4 (dependence on number of IT components) and Figure 5 (dependence on IT components' active lifecycle). 


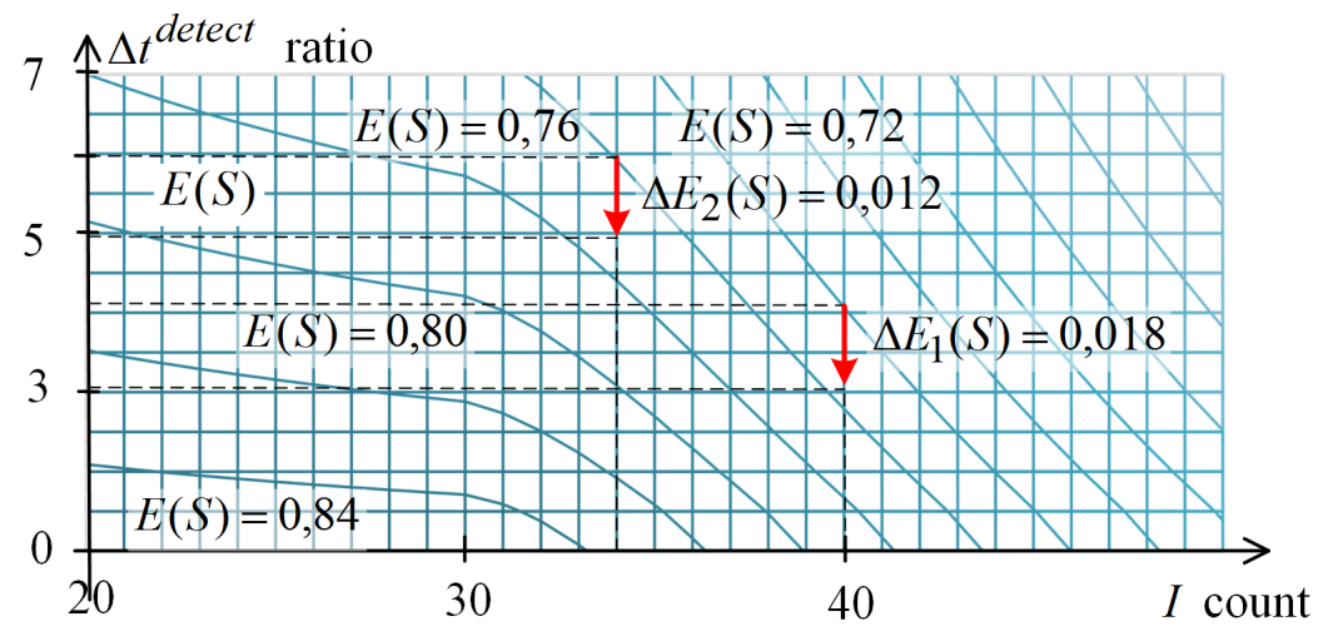

Figure 4. 2D-plot of system effect changing with a number of IT components and moments of reconfiguration $T_{i k}$.

Figures 4-6 show the changes in system effect $E(S)$ as characteristics of IT system suitability. It is noted that the different values of initial system suitability (points 1 and 2 in Figure 4, and points 3 and 4 in Figure 5) leads to a different total effect (with the same decrease in detection time). As we can see, the total effect may be up to 1$3 \%$.

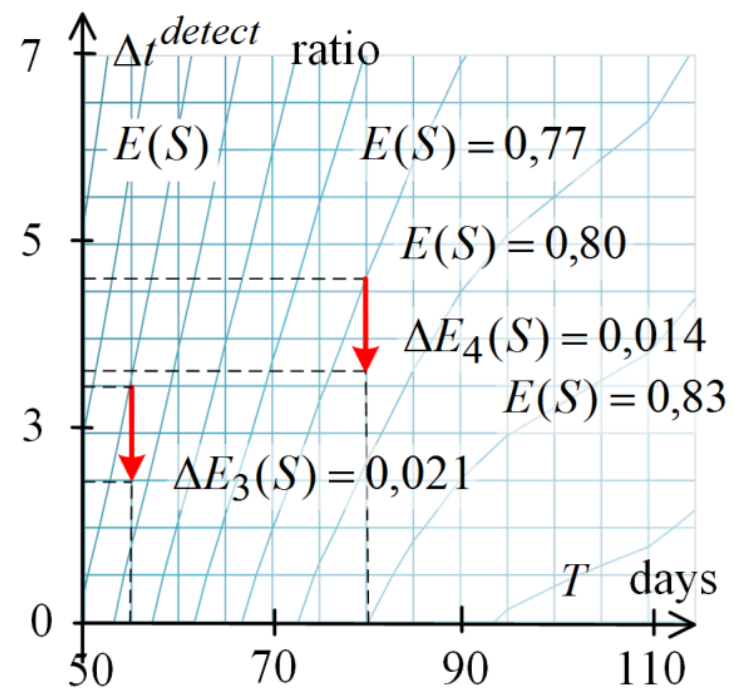

Figure 5. 2D-plot of system effect changing with IT components' active lifecycle and moments of reconfiguration $T_{i k}$. 
The proposed method and relevant integral criteria assume change in significance of functional components over time and thereby provide an increase in effect compared with the method of dynamic priorities by $15-20 \%$ (reduced total planning error). As we can see in Figure 6a, this method allows to increase the suitability factor by $0,5 \%$ to $4 \%$. But if resources are not limited the effect of proposed method is minimal. Figure $6 \mathrm{~b}$ illustrates the suitable factor change $\vartheta=\Delta E(S) / E_{\max }(S)$.
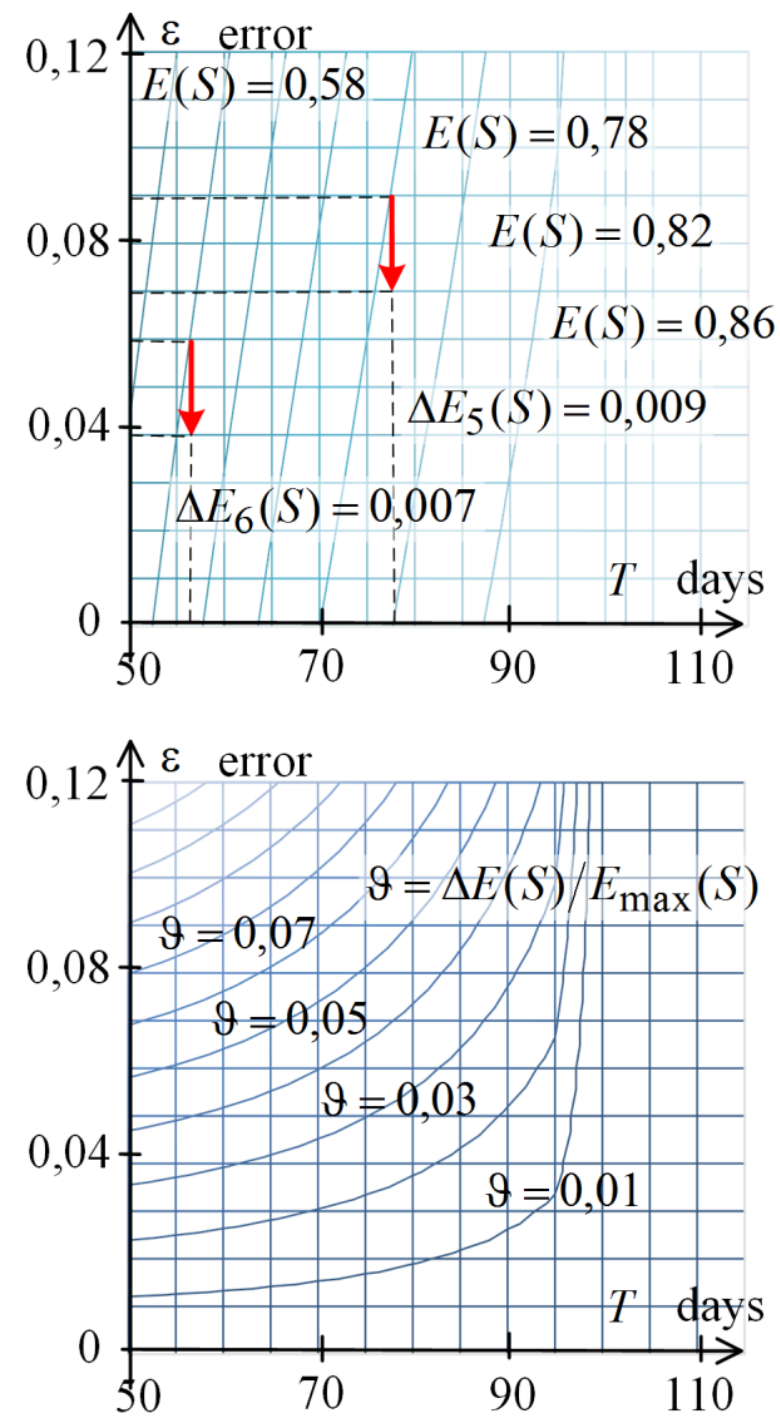

Figure 6. a-2D-plot of system effect changing with IT components' active lifecycle; $b-2 D$-plot of relative system effect.

Research shows that intelligent decision-making methods can improve system reconfiguration by reducing the uncertainty of system data and increase its suitability. 
The effect is the most when resources are significantly limited, and IT components' values change unpredictably over time.

\section{CONCLUSION}

The problem of decision-making for the reconfiguration of adaptive infocommunication system under uncertainty is relevant. To solve this problem, an integrated approach to decision-making for reconfiguration is proposed. It is based on an integral decision-making criterion, selecting a suitable reconfiguration moment and a proper reconfiguration alternative maximizing the integral expected utility.

The main idea of the proposed method is to combine the multifactor active diagnostic model, weighted utility and preference theory, decision-making technique under uncertainty and comparison methods for fuzzy trees with incomplete requirements. The proposed method calculates the decision in four main stages. There are several decision trees proposed for decision-making in special conditions under the uncertainty of implementation time, incomplete requirements, and the uncertain intensity of components' use. The general result is achieved by reducing the uncertainty of diagnostic data.

Results of experiments show that the proposed decision-making methods can generally improve selecting of alternatives for reconfiguration and increase system's suitability. The effect is the most when resources are significantly limited, and IT components' values change unpredictably over time.

\section{ACKNOWLEDGEMENTS}

This work was prepared as part of the implementation of the state task FZWG -20200029 "Development of theoretical foundations for building information and analytical support for telecommunication systems for geo-ecological monitoring of natural resources in agriculture".

\section{REFERENCES}

1. Renna, Paolo. (2017). Decision-making method of reconfigurable manufacturing systems' reconfiguration by a Gale-Shapley model. Journal of Manufacturing Systems. 45. 149-158. 10.1016/j.jmsy.2017.09.005.

2. Derevinsky D. O. Methods of improving the efficiency of business process management on the basis of the theory of restrictions // proceedings of the St. Petersburg University of Economics and Finance. 2012. No. 4. P. 79-82.

3. Kurniadi, Kezia \& Ryu, Kwangyeol. (2017). Development of IOT-based Reconfigurable Manufacturing System to solve Reconfiguration Planning Problem. Procedia Manufacturing. 11. December 2017Procedia Manufacturing 11:965-972, 965-972. 10.1016/j.promfg.2017.07.201. 
4. Sokolov B. V., Zaychik E. M., Ikonnikova A.V., Shaken S. A. Complex planning of modernization of information systems: methodological and methodical bases // Proceedings of spiiran. 2006. Vol.1. No. 3. P. 265-278.

5. Myshenkov K. S., Belyashov A. N. Methodologies, methods and models for analysis and design of control systems. Vestnik MGTU Stankin. 2013. № 3 (26). P. 76-82.

6. V. I. Gurman, I. V. Rasina, O. V. Fesko, Usenko O. V. A Method of improving management for hierarchical models of network structure // News of Irkutsk state University. Series: Mathematics. 2014. Vol. 8. P. 71-85.

7. Graeca O. V., Ponomareva N. With. The conceptual construction of institutional structures in strategy process // News of southern Federal University. Technical science. 2012. № 5 (130). P. 221-226.

8. Han, Sumin \& Chang, Tai-Woo \& Hong, Yoo. (2020). Reconfiguration DecisionMaking of IoT based Reconfigurable Manufacturing Systems. Applied Sciences. 10. 4807. 10.3390/app10144807.

9. Hsieh, Fu-Shiung. (2017). A Meta-Heuristic Approach for Dynamic Process Planning in Reconfigurable Manufacturing Systems. 2017. 18th International Conference on Parallel and Distributed Computing, Applications and Technologies (PDCAT). 164-169. 10.1109/PDCAT.2017.00035.

10. Masucci, Dario \& Foglietta, Chiara \& Palazzo, Cosimo \& Panzieri, Stefano. (2016). Improved Multi-Criteria Distribution Network Reconfiguration with Information Fusion. Conference: FUSION 2016. July 2016. 8p.

11. Niakan, Farzad \& Baboli, Armand \& Moyaux, Thierry \& Botta-Genoulaz, Valérie. (2015). A new multi-objective mathematical model for dynamic cell formation under demand and cost uncertainty considering social criteria. Applied Mathematical Modelling. 10.1016/j.apm.2015.09.047.

12. Benoit, Eric \& Huget, Marc-Philippe \& Moreaux, Patrice \& Passalacqua, Olivier. (2009). Reconfiguration of Distributed Information Fusion System: A case study. IFAC Proceedings Volumes (IFAC-PapersOnline). 2.

13. Colson, Nicolas \& Kountouris, Apostolos \& Wautier, Armelle \& Husson, Lionel. (2008). Autonomous Decision Making Process for the Dynamic Reconfiguration of Cognitive Radios. 1 - 6. 10.1109/ICCCN.2008.ECP.101. Conference: Computer Communications and Networks, 2008. ICCCN '08. Proceedings of 17th International Conference.

14. Lejri, Ons \& Tagina, Moncef. (2012). A Case-Based Reasoning Reconfiguration Decision Support System. International Review on Computers and Software (IRECOS). 7 p.

15. Bernardon, D. \& Garcia, Vinicius \& Ferreira, Adriana \& Canha, Luciane \& Abaide, Alzenira. (2009). Distribution Network Reconfiguration Starting from Fuzzy Multicriteria Decision Making Algorithms. Electronics, Robotics and 
Automotive Mechanics Conference. 440-445. 10.1109/CERMA.2009.56.

16. Huang, Sihan \& Zeng, Cong \& Wang, Guoxin \& Yan, Yan. (2019). Optimal Reconfiguration Path Decision Method for One RMT System. Proceedings of the ASME 2019 International Design Engineering Technical Conferences and Computers and Information in Engineering Conference IDETC/CIE 2019At: Anaheim, California, USA.

17. Mabkhot, Mohammed \& kouki Amri, Sana \& Darmoul, Saber \& Alsamhan, Ali \& Elkosantini, Sabeur. (2019). An ontology based multi-criteria decision support system to reconfigure manufacturing systems. IIE Transactions. 10.1080/24725854.2019.1597317.

18. Shin, Hyun-Jun \& Cho, Kyoung-Woo \& Oh, Chang-Heon. (2018). SVM-Based Dynamic Reconfiguration CPS for Manufacturing System in Industry 4.0. Wireless Communications and Mobile Computing. 2018. 1-13. 10.1155/2018/5795037.

19. Niakan, Farzad \& Baboli, Armand \& Moyaux, Thierry \& Botta-Genoulaz, Valérie. (2015). A new multi-objective mathematical model for dynamic cell formation under demand and cost uncertainty considering social criteria. Applied Mathematical Modelling. 10.1016/j.apm.2015.09.047.

20. Akchurin E. A., Rodionov S. Method of evaluation of quality of communication services provided by providers of fixed communication // Infocommunication technologies. - 2010. - Vol. 8. - № 1. - P. 79-82.

21. Carvalho de Gouveia F., Magadanz T. Quality of service in telecommunication network // Telecommunication Systems and Technologies. 2008 - Vol. II. 21 pp.

22. Wallin S., Leijon V. Multi-Purpose Models for QoS monitoring // 21st Int. Conference on Advanced Information Networking and Applications Workshops. IEEE Computer Society, 2007. Pp. 900-905.

23. Jörgen W. Weibull Discounted-Value Representations of Temporal Preferences // Mathematics of Operations Research, Vol. 10, No. 2 (May, 1985), Pp. 244250.

24. Gerber A., Rohde K. Weighted Temporal Utility // Tinbergen Institute-tute Discussion Papers 13-167/1, Tinbergen Institute. September 26, 2013. 29 p.

25. Frederick S., Loewenstein G., O'donoghue T. Time Discounting and Time Preference: A Critical Review // Journal of Economic Literature, Vol. 40, No. 3. 2. (Jun., 2002), pp. 351-401.

26. Dshemuchadse M., Scherbaum S., Goschke T. How Decisions Emerge: Action Dynamics in Intertemporal Decision Making // Journal of Expert-imental Psychology: General. 2013, Vol. 142, No. 3. 1, 93-100

27. G. Zauberman, B. Kyu Kim, S. A. Malkoc, and Bettman, J. R. Discounting Time and Time Discounting: Subjective Time Perception and Intertemporal 
Preferences // Journal of Marketing Research., August 2009, Vol. 46, No. 46. 4, pp. 543-556.

28.Mishin S. I. Intertemporal preferences in decision-making: experience of experimental research in Russia. Economic journal of HSE. 2012. No. 3. P. 404426.

29. Gigliotti G., Sopher B. Analysis of intertemporal choice: a new framework and experimental results // Theory and Decision, 2004. Vol. 55, pp. 209-233.

30. Pillai J., Vyas O. P., Soni S. A Conceptual Approach to Temporal Weighted Item set Utility Mining // International Journal of Computer Applications, 2010, Volume 1, No. 28, Pp. 55-60.

31. Loginov I. V. Planning of request processing processes in a homogeneous computer network of ASUP on the basis of utility functions. Bulletin of the Ryazan state radio engineering University. 2010. No. 2 (issue 32). P. 105-109.

32. Ivanov A. G. Kukushkin V. A. Dynamics of consumer behavior of the subject // Bulletin of Nizhny Novgorod University. N. So. Lobachevsky. 2010. No. 6. P. 155-163.

33. Kurniadi, Kezia \& Ryu, Kwangyeol. (2017). Development of IOT-based Reconfigurable Manufacturing System to solve Reconfiguration Planning Problem. Procedia Manufacturing. 11. December 2017Procedia Manufacturing 11:965-972, 965-972. 10.1016/j.promfg.2017.07.201.

34. Scholz, Steffen \& Müller, Tobias \& Plasch, Matthias \& Limbeck, Hannes \& Adamietz, R. \& Iseringhausen, Tobias \& Kimmig, Daniel \& Dickerhof, Markus \& Wögerer, C.. (2016). A modular flexible scalable and reconfigurable system for manufacturing of Microsystems based on additive manufacturing and eprinting. August 2016, Robotics and Computer-Integrated Manufacturing 40:1423. 40. 14-23. 10.1016/j.rcim.2015.12.006.

35. Renna, Paolo \& Ambrico, Michele. (2014). Design and reconfiguration models for dynamic cellular manufacturing to handle market changes. International Journal of Computer Integrated Manufacturing. 28. 170-186. 10.1080/0951192X.2013.874590.

36. Wang, Ye \& Tang, Jiafu. (2018). Cost and Service-Level-Based Model for A Seru Production System Formation Problem with Uncertain Demand. Journal of Systems Science and Systems Engineering. 27. 1-19. 10.1007/s11518-0185379-3.

37. Colson, Nicolas \& Kountouris, Apostolos \& Wautier, Armelle \& Husson, Lionel. (2008). Autonomous Decision Making Process for the Dynamic Reconfiguration of Cognitive Radios. 1 - 6. 10.1109/ICCCN.2008.ECP.101. Conference: Computer Communications and Networks, 2008. ICCCN '08. Proceedings of 17th International Conference on

38. Loginov I. V. Application of the tree comparison method to evaluate the quality 
of it services. Information systems and technologies. 2016. № 6 (98). P. 78-88.

39. Kuzichkin, O.R., Loginov, I.V., Eremenko, V.T., Vasilyev, G.S., Grecheneva, A.V. Uncertainty of the implementation time of geodynamic monitoring system in multi-criteria ranking of alternatives // Indonesian Journal of Electrical Engineering and Computer Science. Vol 17. No 3: March 2020. Pp. 1249-1257.

40. Kuzichkin, O.R., Eremenko, V.T., Loginov, I.V., Vasilyev, G.S., Eremenko, A.V., Obozov, A.A. Application of the multi criterial ranking method for the integration of a regional gis into a geotechnical monitoring system // Indonesian Journal of Electrical Engineering and Computer Science 2019

41. Kuzichkin, O.R., Eremenko, V.T., Loginov, I.V., Grecheneva, A.V., Vasilyev, G.S. Approach to the choice of modernization directions for the system of geodynamic monitoring in cases of using components intensity uncertainty // Indonesian Journal of Electrical Engineering and Computer Science. Vol 17. No 3: March 2020. Pp. 1239-1248. 
